\title{
Combined Adsorption and lon Exchange of D-Glyceric Acid Using a Strong Basic Resin: Equilibrium, Kinetics, and Thermodynamics
}

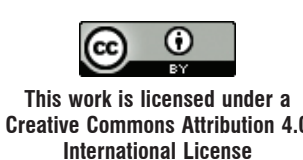

International License

\author{
B. Wang, ${ }^{\mathrm{a}, \mathrm{b}}$ Y. Pu, ${ }^{\mathrm{c}}{ }^{\mathrm{Y}}$. Xie, ${ }^{\mathrm{d}}$ Z. Cai, ${ }^{\mathrm{a}}$ Q. Zheng, ${ }^{\mathrm{a}}$ and Y. $\mathrm{Lu}^{\mathrm{c},{ }^{, *}}$ \\ ${ }^{a}$ College of Oceanology and Food Science, \\ Quanzhou Normal University, Quanzhou 362000, China \\ ${ }^{b}$ Fujian Province Key Laboratory for the Development \\ of Bioactive Material from Marine Algae, Quanzhou 362000, China \\ 'Department of Chemical and Biochemical Engineering, \\ College of Chemistry and Chemical Engineering, \\ Xiamen University, Xiamen 361005, China \\ ${ }^{\mathrm{d} C o l l e g e}$ of Biological Science and Engineering, \\ Fuzhou University, Fuzhou 350108, China
}

doi: 10.15255/CABEQ.2017.1112

Original scientific paper

Received: March 7, 2017

Accepted: November 6, 2017

\begin{abstract}
D-Glyceric acid (D-GA) is a glycerol derivative with various promising biological functions. This paper reports the adsorption of D-GA from aqueous solution using a strong basic resin. The effect of $\mathrm{pH}$ on the uptake of D-GA was studied, and several models were used to investigate the interactions of D-GA and the resin. A theoretical model based on ion exchange and adsorption was developed to fit the isotherms under various $\mathrm{pH}$ or temperatures. Kinetic experiments under different initial D-GA concentrations were also performed to define the controlling mechanism of the overall adsorption process. The results showed that the uptake process of D-GA was controlled by the rate of D-GA diffusion through the polymeric matrix of the resin. This study provides valuable information and theoretical support for the scale-up and optimization of operating conditions for the recovery of D-GA.
\end{abstract}

Key words:

D-glyceric acid, ion exchange, adsorption, film diffusion, resin $201 \times 7$

\section{Introduction}

Glyceric acid (2,3-dihydroxypropionic acid; GA) is a useful glycerol derivative, widely used in chemical products synthesis ${ }^{1}$, cosmetics $^{2}$, and pharmaceuticals ${ }^{3}$. D-Glyceric acid (D-GA) was reported to have biological functions including accelerating ethanol and acetaldehyde oxidation ${ }^{4}$ and enhancing the viability of ethanol-dosed gastric cells ${ }^{3}$. Therefore, it is a promising chemical for minimizing the toxic effect of acetaldehyde, the metabolite of alcohol. Fed-batch fermentation has been used successfully to produce D-GA ${ }^{4,5}$. However, few previous studies on downstream processes to recover D-GA were available. Ion exchange is widely used in separation of several carboxylic acids and weak acids $^{6-9}$. It is easy to scale-up and apply to industrial manufacturing processes, and the purification process is inexpensive. Basic anionic exchange resins (IRA400, IRN78) have been shown to separate GA and lactic acid from the cleavage solution success-

"Corresponding author: Yinghua Lu (ylu@xmu.edu.cn);

Tel: +86-592-2183751, Fax: +86-592-2186400 fully ${ }^{10}$. However, few studies addressed the basic attributes of the equilibrium and the kinetics and thermodynamics of ion exchange resins used for D-GA separation.

In this study, the adsorption of D-GA from an aqueous solution was evaluated using a strong basic exchange resin (denoted by $201 \times 7$ ). The effect of $\mathrm{pH}$ on the uptake of D-GA by basic resin was studied, and a theoretical model based on ion exchange and adsorption was developed to study the adsorption mechanisms. Kinetic experiments under different initial D-GA concentrations were also performed to define the controlling mechanism of the overall adsorption process.

\section{Materials and methods}

\section{Materials}

D-GA with purity higher than $98 \%$ was supplied by Sigma-Aldrich. The $201 \times 7$ resin used in this study was purchased from Xilong Chemical Co., Ltd., China. 
Table $1-$ Physical and chemical properties of the $201 \times 7$ resin

\begin{tabular}{|c|c|}
\hline Type & Strong basic anion exchanger \\
\hline Polymer matrix & Polystyrene DVB \\
\hline Standard ionic form & $\mathrm{Cl}^{-}\left(\mathrm{OH}^{-}\right)$ \\
\hline Functional structure & $-\mathrm{N}^{+}\left(\mathrm{CH}_{3}\right)_{3}$ \\
\hline Appearance & $\begin{array}{l}\text { Yellow to golden spherical beads, } \\
\text { translucent }\end{array}$ \\
\hline Effective diameter & $0.40-0.70 \mathrm{~mm}$ \\
\hline Moisture content & $53 \%-58 \%$ \\
\hline $\begin{array}{l}\text { Shipping density in wet } \\
\text { state }\end{array}$ & $0.66-0.71$ \\
\hline True density in wet state & $1.06-1.19$ \\
\hline Operating $\mathrm{pH}$ range & $0-14$ \\
\hline $\begin{array}{l}\text { Maximum operating } \\
\text { temperature }\end{array}$ & $\leq 80^{\circ} \mathrm{C}\left(\mathrm{Cl}^{-}\right) ; \leq 60^{\circ} \mathrm{C}\left(\mathrm{OH}^{-}\right)$ \\
\hline
\end{tabular}

\section{Resin characteristics}

The main characteristics of the $201 \times 7$ resin, a strong basic anion resin, are presented in Table 1.

\section{Pre-treatment of resin}

The resin was pre-treated by repeated washing with $2 \mathrm{M} \mathrm{NaOH}$ and $2 \mathrm{M} \mathrm{HCl}$ solutions, and then converted to the hydroxide form by elution with 2 $\mathrm{M} \mathrm{NaOH}$, and rinsed at neutral $\mathrm{pH}$ with deionized water. The resin was subsequently dried at $50{ }^{\circ} \mathrm{C}$.

\section{Quantification of GA}

D-GA concentration was determined by high-performance liquid chromatography (HPLC) according to the method described by Habe et al. ${ }^{5}$

\section{Equilibrium experiments}

Equilibrium batch experiments were performed at a series of $\mathrm{pH}$ values and temperatures. Specifically, $0.5 \mathrm{~g}$ of dry resin was mixed with aqueous solutions of D-GA with different initial concentrations and at varying $\mathrm{pH}$ values $(8-12)$. The D-GA content in each aqueous solution was then quantified by HPLC. The adsorption capacity at equilibrium $\left(q_{e}, \mathrm{~mol} \mathrm{~kg}^{-1}\right.$ dry resin) was determined as follows:

$$
q_{\mathrm{e}}=\left(C_{0}-C_{\mathrm{e}}\right) \cdot \frac{V}{m}
$$

where $C_{0}$ and $C_{\mathrm{e}}$ are the initial and equilibrium concentrations of D-GA in the liquid phase $\left(\mathrm{mol} \mathrm{L}^{-1}\right)$, respectively; $V(\mathrm{~L})$ is the volume of the solution, and $m(\mathrm{~kg})$ is the mass of the dry ion exchange resin.

\section{Kinetics experiments}

The kinetics of the reaction was studied by measuring the rate of D-GA uptake from the liquid phase by the resin at various initial concentrations and at $\mathrm{pH}$ 8. The experiments were carried out at $25^{\circ} \mathrm{C}$. In a typical experiment, $0.5 \mathrm{~g}$ of resin was mixed with varying concentrations of D-GA solution.

\section{Results and discussion}

\section{Adsorption equilibrium}

Effect of $\mathrm{pH}$ on adsorption equilibrium

The adsorption isotherm for D-GA onto the $201 \times 7$ resin at various initial $\mathrm{pH}$ values is shown in Fig. 1. The maximum adsorption capacity increased as $\mathrm{pH}$ decreased. Langmuir ${ }^{11}$, Freundlich, ${ }^{12,13}$ and Radke-Prausnitz ${ }^{14}$ isotherms were used to analyze

Table 2 -Langmuir, Freundlich and Radke-Prausnitz isotherm parameters for D-GA adsorption on the resin $201 \times 7$

\begin{tabular}{|c|c|c|c|c|c|c|c|c|c|c|}
\hline \multirow{2}{*}{$\mathrm{pH}$} & \multicolumn{3}{|c|}{$\begin{array}{c}\text { Langmuir } \\
q_{\mathrm{e}}=\frac{q_{\mathrm{m}} K_{\mathrm{L}} C_{\mathrm{e}}}{1+K_{\mathrm{L}} C_{\mathrm{e}}}\end{array}$} & \multicolumn{3}{|c|}{$\begin{array}{l}\text { Freundlich } \\
\qquad q_{\mathrm{e}}=k C_{\mathrm{e}}^{\frac{1}{n}}\end{array}$} & \multicolumn{4}{|c|}{$\begin{array}{l}\text { Radke-Prausnitz } \\
q_{\mathrm{e}}=\frac{K q_{\mathrm{m}} C_{\mathrm{e}}}{\left(1+K C_{\mathrm{e}}\right)^{m}}\end{array}$} \\
\hline & $R^{2}$ & $\begin{array}{c}K_{\mathrm{L}} \\
\left(\mathrm{L} \mathrm{mol}^{-1}\right)\end{array}$ & $\begin{array}{c}q_{\mathrm{m}} \\
\left.(\mathrm{mol} \mathrm{kg})^{-1}\right)\end{array}$ & $R^{2}$ & $\begin{array}{c}k \\
\left(\mathrm{~mol} \mathrm{~kg}^{-1}\right) \\
\left(\mathrm{g} \mathrm{L}^{-1}\right)^{-1 / \mathrm{n}}\end{array}$ & $n$ & $R^{2}$ & $K\left(\mathrm{~L} \mathrm{~mol}^{-1}\right)$ & $\begin{array}{c}q_{\mathrm{m}} \\
\left(\mathrm{mol} \mathrm{kg}^{-1}\right)\end{array}$ & $m$ \\
\hline 8 & 0.876 & 241.56 & 1.900 & 0.990 & 3.52 & 4.16 & 0.987 & $1.12 \cdot 10^{7}$ & 0.071 & 0.760 \\
\hline 9 & 0.904 & 207.84 & 1.769 & 0.997 & 3.43 & 3.92 & 0.996 & $4.33 \cdot 10^{6}$ & 0.069 & 0.745 \\
\hline 10 & 0.943 & 121.77 & 1.808 & 0.994 & 3.68 & 3.32 & 0.992 & $8.49 \cdot 10^{3}$ & 0.253 & 0.706 \\
\hline 11 & 0.961 & 190.84 & 1.457 & 0.980 & 2.72 & 3.98 & 0.983 & $9.79 \cdot 10^{2}$ & 0.625 & 0.809 \\
\hline 12 & 0.998 & 70.36 & 1.547 & 0.956 & 3.42 & 2.71 & 0.998 & 48.12 & 2.061 & 1.143 \\
\hline
\end{tabular}



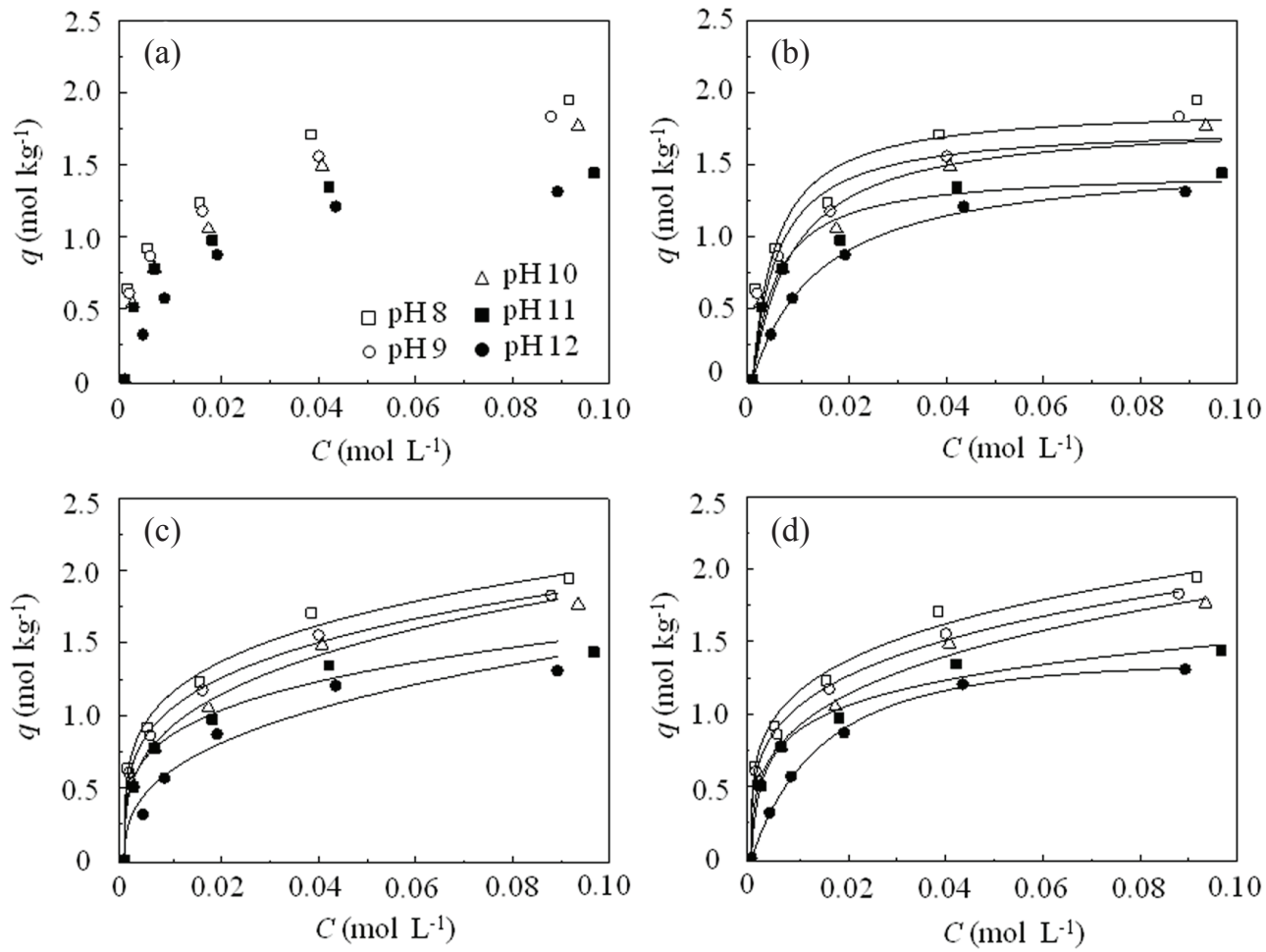

Fig. 1 - Adsorption isotherms of D-GA at varying initial pH values (a) experimental points (b) Langmuir fitting (c) Freundlich fitting (d) Radke-Prausnitz fitting (Baobei Wang et al. Combined adsorption and ion exchange of D-glyceric acid using a strong basic resin: equilibrium, kinetics, and thermodynamics)

the equilibrium data (Fig. 1). The parameters of each isotherm are listed in Table 2. As the $\mathrm{pH}$ value was higher, the better the fit was between the equilibrium data and the Langmuir isotherm model. The Langmuir model fit the experimental data well with an initial $\mathrm{pH}$ of 12 . Both the Freundlich and Radke-Prausnitz models fit the experimental data well. All $n$ values in the Freundlich model at various initial $\mathrm{pH}$ values were between $1<n<10$, indicating that the resin had a favorable adsorption for D-GA ${ }^{8}$.

The empirical equilibrium models do not allow us to distinguish between the mechanisms that occur by the combined effect of molecular adsorption and ion exchange, and those that are affected by ion exchange alone. Thus, in order to determine the contribution of each phenomenon to D-GA removal, a new model based on both molecular adsorption and ion exchange mechanisms was developed, and is presented in the following section.

\section{Theoretical procedure}

\section{(1) Liquid phase}

In the liquid phase, D-GA dissociation takes place according to its $\mathrm{p} K$ a values (3.64). The following D-GA dissociation reactions occur in aqueous solution as a function of $\mathrm{pH}$ :

$$
\mathrm{GA}^{\mathrm{COOH}} \leftrightarrows \mathrm{GA}^{\mathrm{COO}}+\mathrm{H}^{+}
$$

From Eq. (2):

$$
K_{\mathrm{GA}}=\frac{\left[\mathrm{GA}^{\mathrm{COO}}\right]\left[\mathrm{H}^{+}\right]}{\left[\mathrm{GA}^{\mathrm{COOH}}\right]}
$$

where $\left[\mathrm{GA}^{\mathrm{COOH}}\right]$ is the D-GA concentration, [GA $\left.{ }^{\mathrm{COO}}-\right]$ is the ionic D-GA concentration, and $K_{\mathrm{GA}}$ is the equilibrium constant for D-GA dissociation in the liquid phase.

The total amount of D-GA measured is equal to both forms of D-GA, i.e.:

$$
\left[\mathrm{GA}_{\text {measured }}\right]=\left[\mathrm{GA}^{\mathrm{COOH}}\right]+\left[\mathrm{GA}^{\mathrm{COO}^{\circ}}\right]
$$

where $\left[\mathrm{GA}_{\text {measured }}\right]$ is the total amount of D-GA that is experimentally measured.

Substituting the last equation into Eq. (3), one gets:

$$
\left[\mathrm{GA}^{\mathrm{COO}^{-}}\right]=\frac{\left[\mathrm{GA}_{\text {measured }}\right]}{1+\left[\mathrm{H}^{+}\right] / K_{\mathrm{GA}}}
$$

The hydrogen concentration can be obtained if the $\mathrm{pH}$ is known, so Eq. (5) becomes:

$$
\left[\mathrm{GA}^{\mathrm{COO}^{-}}\right]=\frac{\left[\mathrm{GA}_{\text {measured }}\right]}{1+10^{\mathrm{pK}_{\mathrm{a}}-\mathrm{pH}}}
$$

Eq. (6) allows the concentration of glycerate in solution to be determined as a function of the total concentration of D-GA and the $\mathrm{pH}$ of the liquid solution. The relationship between $\mathrm{pH}$ and the relative concentrations of D-glyceric acid and D-glycerate with respect to the total concentration of D-GA in solution is shown in Fig. 2. 


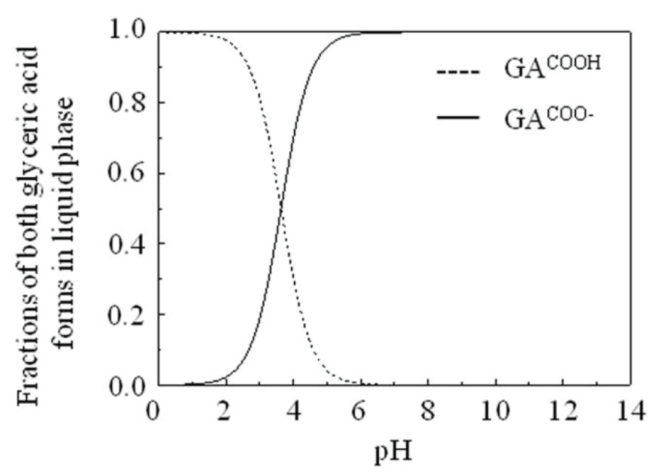

Fig. 2 - Effect of the $p H$ on D-GA dissolution

\section{(2) Solid phase}

In the solid phase, ionic D-GA binds to the resin through ion exchange. The ion exchange uptake of D-GA by the resin (the first uptake layer) can be described by the following equation:

$$
\begin{gathered}
\mathrm{R}^{+} \mathrm{OH}^{-}+\mathrm{GA}^{\mathrm{COO}} \leftrightarrows \mathrm{R}^{+} \mathrm{GA}^{\mathrm{COO}^{-}}+\mathrm{OH}^{-} \\
K_{\mathrm{IE}}=\frac{\left[\mathrm{R}^{+} \mathrm{GA}^{\mathrm{COO}}\right]\left[\mathrm{OH}^{-}\right]}{\left[\mathrm{R}^{+} \mathrm{OH}^{-}\right]\left[\mathrm{GA}^{\mathrm{COO}-}\right]} \\
q_{\mathrm{IE}}=\frac{q_{\mathrm{m}, \mathrm{IE}} K_{\mathrm{IE}}\left[\mathrm{GA}^{\mathrm{COO}}\right]}{\left[\mathrm{OH}^{-}\right]+K_{\mathrm{IE}}\left[\mathrm{GA}^{\mathrm{COO}^{-}}\right]}
\end{gathered}
$$

where $q_{\mathrm{mIE}}$ is the maximum ion exchange capacity of the resin, $K_{\mathrm{IE}}$ is the ion exchange separation factor, and $q_{\mathrm{IE}}$ is the equilibrium concentration of glycerate in the solid phase.

Substituting Eq. (6) into Eq. (9), one obtains the following:

$$
\frac{q_{\mathrm{m}, \mathrm{IE}} K_{\mathrm{IE}}\left[\mathrm{GA}_{\text {measured }}\right]}{10^{\mathrm{pH}-14}+10^{\mathrm{pKa}-14}+K_{\mathrm{IE}}\left[\mathrm{GA}_{\text {measured }}\right]}=q_{\mathrm{e}}
$$

However, Eq. (10) does not fit the experimental data well (data not shown), indicating that the binding of D-GA to the resin is probably not only due to ion exchange.

As there are two hydroxyl groups in the D-GA molecule, an intermolecular hydrogen bond probably forms between D-GA molecules. Therefore, we assume that there are two mechanisms (ion exchange and adsorption) for the uptake of D-GA into the resin beads. Ionic D-GA attaches to the resin through ion exchange to form the first uptake layer, which supports hydrogen bond donors that adsorb free D-GA in solution to form a second uptake layer. The formation of hydrogen bonds between molecules is based on the binding site of the hydrogen bond; therefore, both ionic D-GA and molecular D-GA are adsorbed. The second uptake layer is characterized by the adsorption process. If the adsorption process is assumed to be restricted to a single monolayer, the Langmuir equation (Table 2) can be used to represent the adsorption equilibrium,

$$
\begin{gathered}
\mathrm{R}^{+}-\mathrm{GA}^{\mathrm{COO}}+\mathrm{GA} \leftrightarrows \mathrm{R}^{+}-\mathrm{GA}^{\mathrm{COO}}-\mathrm{GA} \\
q_{\mathrm{Ad}}=\frac{q_{\mathrm{m}, \mathrm{Ad}} K_{\mathrm{Ad}}\left[\mathrm{GA}_{\text {measured }}\right]}{1+K_{\mathrm{Ad}}\left[\mathrm{GA}_{\text {measured }}\right]}
\end{gathered}
$$

where $q_{\text {m,Ad }}$ is the maximum adsorption capacity of the resin, $K_{\mathrm{Ad}}$ is the adsorption separation factor, and $q_{\mathrm{Ad}}$ is the equilibrium concentration of the D-GA adsorbed by hydrogen bonds in the solid phase.

Each D-GA attached onto the resin in the first uptake layer is inclined to bind with a D-GA molecule via hydrogen bonding. Though there are two hydroxyl groups in each D-GA molecule, the steric hindrance effect makes it difficult for the D-GA molecule in the first uptake layer to form a hydrogen bond with a second D-GA. Accordingly, the maximum capacity of the adsorption process in the second layer is equal to that of the ion exchange process:

$$
q_{\mathrm{m}, \mathrm{Ad}}=q_{\mathrm{m}, \mathrm{IE}}
$$

Taking into account the two mechanisms of uptake in the solid phase, the following mass balance can be drawn:

$$
q_{\mathrm{IE}}+q_{\mathrm{Ad}}=q_{e}
$$

Substituting the ion exchange and adsorption mechanisms into the mass balance equation, Eq. (14) becomes

$$
\frac{q_{\mathrm{m}, \mathrm{IE}} K_{\mathrm{IE}}\left[\mathrm{GA}^{\mathrm{COO}-}\right]}{\left[\mathrm{OH}^{-}\right]+K_{\mathrm{IE}}\left[\mathrm{GA}^{\mathrm{COO}-}\right]}+\frac{q_{\mathrm{m}, \mathrm{IE}} K_{\mathrm{Ad}}\left[\mathrm{GA}_{\text {measured }}\right]}{1+K_{\mathrm{Ad}}\left[\mathrm{GA}_{\text {measured }}\right]}=q_{\mathrm{e}}
$$

Substituting Eq. (6) into Eq. (15), we obtain the following:

$$
\begin{aligned}
& q_{\mathrm{m}, \mathrm{IE}}\left(\frac{K_{\mathrm{IE}}\left[\mathrm{GA}_{\text {measured }}\right]}{10^{\mathrm{pH}-14}+10^{\mathrm{p} K a-14}+K_{\mathrm{IE}}\left[\mathrm{GA}_{\text {measured }}\right]}+\right. \\
& \left.+\frac{K_{\mathrm{Ad}}\left[\mathrm{GA}_{\text {measured }}\right]}{1+K_{\mathrm{Ad}}\left[\mathrm{GA}_{\text {measured }}\right]}\right)=q_{\mathrm{e}}
\end{aligned}
$$

The above equation describes the removal of D-GA by the resin in terms of three unknown parameters $\left(K_{\mathrm{IE}}, K_{\mathrm{Ad}}, q_{\mathrm{m}, \mathrm{IE}}\right)$ related to ion exchange and adsorption. Experimental data were fitted to Eq. (16) by a non-linear least-squares regression procedure (Fig. 3). The values of the parameters obtained by fitting the experimental data to this model are shown in Table 3. According to these results, we conclude that both phenomena (ion exchange and adsorption) occur during the D-GA uptake process. This result shows that the value of $K_{\mathrm{Ad}}(16.5)$ is much greater than that of $K_{\mathrm{IE}}(2.40)$.

According to Eq. (16), the uptake capacity of D-GA onto the $201 \times 7$ resin increases with decreasing $\mathrm{pH}$. This result is in accordance with the exper- 


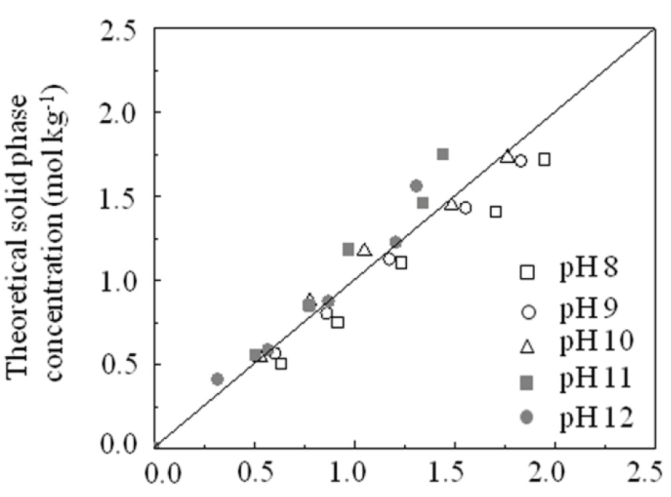

Experimental solid phase concentration $\left(\mathrm{mol} \mathrm{kg}^{-1}\right)$

Fig. 3 - Reproducibility of the experimental data by the theoretical model

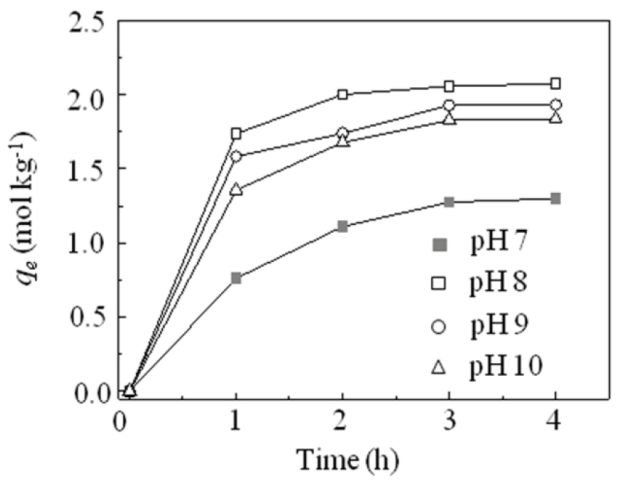

Fig. 4 - Effect of initial $p H$ value on the uptake of D-GA

imental isotherm result, which indicated that the uptake capacity with $\mathrm{pH} 8$ was greater than in other initial $\mathrm{pH}$ conditions (Fig. 1). However, the percentage of ionic D-GA in solution decreases with decreasing $\mathrm{pH}$, which decreases the ion exchange capacity. Therefore, to gain a maximum uptake capacity, a suitable initial $\mathrm{pH}$ in solution is important. As shown in Fig. 2, when the $\mathrm{pH}$ value is higher than $6.0,99 \%$ of D-GA exists in ionic form. Therefore, there may be a larger uptake capacity at $\mathrm{pH}$ lower than 8. Another experiment was performed to determine the maximum uptake capacity. However, the result showed that the uptake capacity at $\mathrm{pH} 7$ was less than that at $\mathrm{pH} \mathrm{8}$, and the maximum uptake capacity $\left(2.07 \mathrm{~mol} \mathrm{\textrm {kg } ^ { - 1 }}\right)$ was achieved at $\mathrm{pH} 8$ (Fig. 4), which was similar to the maximum two-layer adsorption capacity $\left(2.24 \mathrm{~mol} \mathrm{\textrm {kg } ^ { - 1 }}\right)$ gained by the theoretical model (Eq. 16). This result is likely due to the effect of $\mathrm{pH}$ on the hydrogen bond interaction of D-GA in solution.

\section{Effect of temperature on adsorption}

Changes in the Gibbs free energy $(\Delta G)$, enthalpy $(\Delta H)$, and entropy $(\Delta S)$ are important thermodynamic parameters that can be determined using the following equations.
Table 3 -Equilibrium parameters in Eq. (16) of D-GA on the resin $201 \times 7$

\begin{tabular}{cc}
\hline Parameters & Value \\
\hline$q_{\mathrm{IE}}\left(\mathrm{mol} \mathrm{kg}^{-1}\right)$ & 1.12 \\
$K_{\mathrm{IE}}$ & 2.40 \\
$K_{\mathrm{AD}}$ & 16.5 \\
Average deviation $(\%)=$ & 8.94 \\
$=\sum_{i=1}^{m} \frac{\text { abs }\left(\left(q_{i}^{\text {exp }}-q_{i}^{\text {theor }}\right) / q_{i}^{\text {exp }}\right) \cdot 100}{m}$ & \\
\hline
\end{tabular}

$m$ : total number of experimental data

$$
\begin{gathered}
\Delta G=-R T \ln K \\
\Delta G=\Delta H-T \Delta S
\end{gathered}
$$

where $K\left(\mathrm{~L} \mathrm{~mol}^{-1}\right)$ is the equilibrium constant, $T(\mathrm{~K})$ is the absolute temperature, and $R$ is the universal gas constant $\left(8.314 \cdot 10^{-3} \mathrm{~kJ} \mathrm{~K}^{-1} \mathrm{~mol}^{-1}\right)$.

Combining Eqs. (17) and (18) leads to:

$$
K=\exp \left(\frac{\Delta S}{R}-\frac{\Delta H}{R T}\right)
$$

The equilibrium data at various temperatures are shown in Fig. 5a, which suggests that the solution temperature has little effect on the maximum adsorption capacity. Therefore, $q_{\mathrm{m}}$ was assumed to be constant. Substituting Eq. (19) into our theoretical model (Eq. (16)) leads to:

$$
\begin{aligned}
& q_{\mathrm{m}, \mathrm{IE}} \cdot\left(\frac{\exp \left(\frac{\Delta S_{\mathrm{IE}}}{R}-\frac{\Delta H_{\mathrm{IE}}}{R T}\right)\left[\mathrm{GA}_{\text {measured }}\right]}{10^{\mathrm{pH}-14}+10^{\mathrm{pKa}-14}+\exp \left(\frac{\Delta S_{\mathrm{IE}}}{R}-\frac{\Delta H_{\mathrm{IE}}}{R T}\right)\left[\mathrm{GA}_{\text {measured }}\right]}+\right. \\
& \left.+\frac{\exp \left(\frac{\Delta S_{\mathrm{Ad}}}{R}-\frac{\Delta H_{\mathrm{Ad}}}{R T}\right)\left[\mathrm{GA}_{\text {measured }}\right]}{1+\exp \left(\frac{\Delta S_{\mathrm{Ad}}}{R}-\frac{\Delta H_{\mathrm{Ad}}}{R T}\right)\left[\mathrm{GA}_{\text {measured }}\right]}\right)=q_{\mathrm{e}}
\end{aligned}
$$

$q_{\mathrm{m}, \mathrm{IE}}$ in Eq. 20 refers to the maximum uptake capacity of D-GA with solution $\mathrm{pH}$ value of 8 at varying temperatures $(293 \sim 303 \mathrm{~K})$. Whereas, $q_{\mathrm{m}, \mathrm{IF}}$ in Eq. 16 refers to the maximum uptake capacity of D-GA with varying solution $\mathrm{pHs}$ at $298 \mathrm{~K}$.

The experimental adsorption isotherms and those predicted by the theoretical model at various temperatures are shown in Fig. 5b. The parameters obtained by fitting the experimental data to this model are listed in Table 4 . The positive value of $\Delta H_{1}$ and $\Delta H_{2}$ indicates that both ion exchange and the adsorption process are endothermic processes. Both uptake processes are spontaneous, as demonstrated by the negative $\Delta G_{1}$ and $\Delta G_{2}$ values (calculated according to Eq. (18)). 
Table 4 -Equilibrium parameters in Eq. (20) of D-GA on the resin $201 \times 7$

\begin{tabular}{cc}
\hline Parameters & Value \\
\hline$q_{\mathrm{m}, \mathrm{IE}}\left(\mathrm{mol} \mathrm{kg}^{-1}\right)$ & 0.939 \\
$\Delta S_{1}\left(\mathrm{~J} \mathrm{~mol}^{-1} \mathrm{~K}^{-1}\right)$ & 377 \\
$\Delta H_{1}\left(\mathrm{~kJ} \mathrm{~mol}^{-1}\right)$ & 107 \\
$\Delta S_{2}\left(\mathrm{~J} \mathrm{~mol}^{-1} \mathrm{~K}^{-1}\right)$ & 145 \\
$\Delta H_{2}\left(\mathrm{~kJ} \mathrm{~mol}^{-1}\right)$ & 34.0 \\
Average deviation $(\%)=$ & \\
$=\sum_{i=1}^{m} \frac{\text { abs }\left(\left(q_{i}^{\text {exp }}-q_{i}^{\text {theor }}\right) / q_{i}^{\text {exp }}\right) \cdot 100}{m}$ & \\
\hline
\end{tabular}

$m$ : total number of experimental data

\section{Kinetics}

Studies of adsorption kinetics were performed to explain the mechanism of interaction between the adsorbate and the adsorbent, and to understand the rate-controlling step. The mechanisms of the adsorption process can be described as follows ${ }^{12,15}$ : (1) solute diffuses through the liquid film surrounding the particle (film diffusion control), (2) solute diffuses through the polymeric matrix of the resin (particle diffusion control); (3) chemical reaction. The step offering greater resistance than the others is considered the rate-controlling step. When the porosity of the polymer is small, and thus the polymer is practically impervious to the fluid reactant, the adsorption process may be explained by the "shell progressive" approach. The kinetic concept of a shell progressive mechanism (SPM) can be described in terms of the concentration profile of a liquid reactant containing a solute advancing into a spherical bead partially saturated with the adsorbent. In this case, the relationship between the adsorption time and the degree of adsorption is given by the following expressions. ${ }^{11}$

(1) Fluid film control:

$$
F=\frac{3 C_{0} K_{\mathrm{f}}}{a C_{\mathrm{m}} r} t
$$

(2) Diffusion control

$$
\left[3-3(1-F)^{2 / 3}-2 F\right]=\frac{6 D_{\mathrm{e}} C_{0}}{a C_{\mathrm{m}}{ }^{2}} t
$$

(3) Chemical reaction control

$$
1-(1-F)^{1 / 3}=\frac{K_{\mathrm{c}} C_{0}}{r} t
$$

In order to understand the ion exchange kinetic process and to define the rate-controlling step during the D-GA uptake, the shell progressive model (SPM) was selected to describe the ion exchange data. The evolution of the D-GA uptake, $q\left(\mathrm{~mol} \mathrm{~kg}{ }^{-1}\right.$
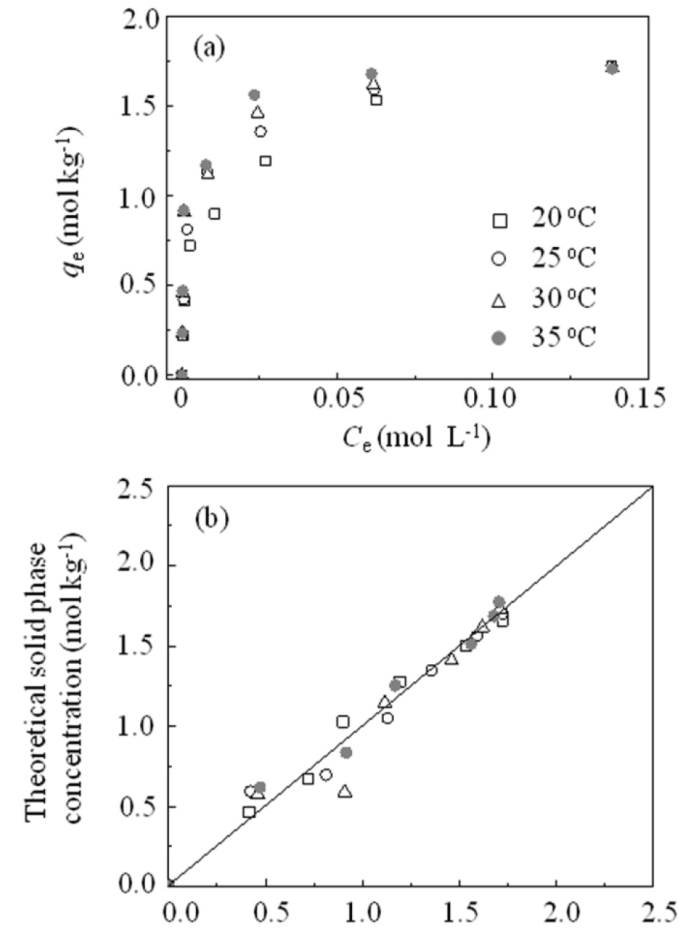

Experimental solid phase concentration $\left(\mathrm{mol} \mathrm{kg}^{-1}\right)$

Fig. 5-Experimental and the theoretically predicted adsorption isotherms of D-GA at varying temperatures (a) experimental points (b) reproducibility of the experimental data by the theoretical model

dry resin), with time at varying initial concentrations is shown in Fig. 6. Descriptions of the kinetic data using the SPM model (Eqs. (21) - (23)) for D-GA are listed in Table 5.

The correlation coefficient was used to evaluate the quality of fit for each case. High correlation coefficients $\left(R^{2}>0.98\right)$ revealed that the film diffusion model fit the experimental data satisfactorily for the entire time range, indicating that particle diffusion is most likely the rate-controlling step during the process of D-GA uptake. The slope values were used to calculate effective diffusion coefficients for the different D-GA concentrations using Eqs. (21) - (23). The diffusion coefficients calculated in this manner were a measure of the mean inter-diffusion coefficient of the D-GA molecules involved in the adsorption process. The mean inter-diffusion coefficients given by the SPM model decreased as the initial D-GA concentration increased. The variation of $D_{\mathrm{e}}$ was consistent with that found in the literature for weak acids separation ${ }^{11,15}$.

\section{Conclusions}

The strong basic exchange resin $(201 \times 7)$ was demonstrated to be effective for D-GA separation. The uptake capacity is affected by the initial $\mathrm{pH}$ of the solution, and the maximum uptake capacity was 

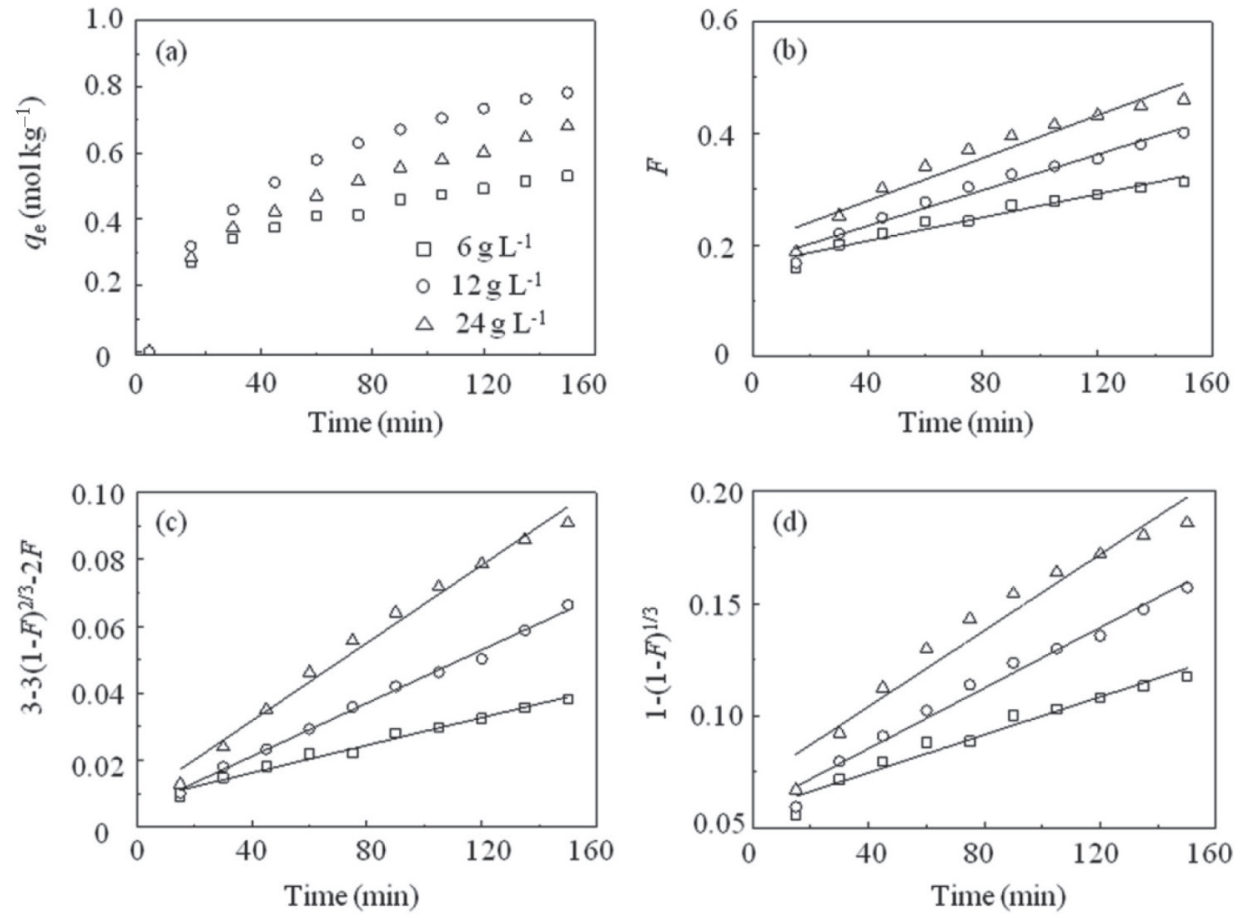

Fig. 6 - Experimental data and shell progressive model fitting for adsorption of D-GA onto the resin with varying initial concentrations (a) experimental data (b) fluid film control (c) diffusion control (d) chemical reaction control

Table 5 - Linear regression analysis of SPM model for D-GA uptake at varying initial concentrations

\begin{tabular}{c|cccc|ccc}
\hline & \multicolumn{3}{c|}{$F$} & \multicolumn{2}{c}{$\left[3-3(1-F)^{2 / 3}-2 F\right]$} & $1-(1-F)^{1 / 3}$ & $K_{\mathrm{c}}$ \\
\hline $\begin{array}{c}\text { Concentration } \\
\left(\mathrm{g} \mathrm{L}^{-1}\right)\end{array}$ & $R^{2}$ & $K_{\mathrm{f}}\left(\mathrm{cm} \mathrm{s}^{-1}\right)$ & $R^{2}$ & $\begin{array}{c}D_{\mathrm{e}} / a \\
\left(\mathrm{~cm}^{2} \mathrm{~s}^{-1}\right)\end{array}$ & $R^{2}$ & $\begin{array}{c}\left(\mathrm{cm} \mathrm{s}^{-1}\right) \\
6\end{array}$ \\
12 & 0.945 & $1.31 \cdot 10^{-5}$ & 0.983 & $6.44 \cdot 10^{-8}$ & 0.954 & $3.52 \cdot 10^{-6}$ \\
24 & 0.968 & $1.00 \cdot 10^{-5}$ & 0.995 & $6.02 \cdot 10^{-8}$ & 0.978 & $2.81 \cdot 10^{-6}$ \\
& 0.926 & $5.97 \cdot 10^{-6}$ & 0.985 & $4.54 \cdot 10^{-8}$ & 0.946 & $1.77 \cdot 10^{-6}$ \\
\hline
\end{tabular}

obtained at $\mathrm{pH}$ 8. In order to model the equilibrium of D-GA on the resin, the uptake of D-GA was determined by both empirical and theoretical method. The Freundlich and Radke-Prausnitz models fit the equilibrium model well. A theoretical model based on ion exchange and adsorption was developed to fit the experimental data, and the parameters related to both phenomena were determined. The theoretical treatment allows us to verify that the uptake capacity increases as $\mathrm{pH}$ decreases, which is consistent with the experimental data. Our result also showed that temperature has little effect on the maximum uptake capacity, and both ion exchange and the adsorption process are endothermic and spontaneous processes.

With respect to the kinetic experiments, the shell progressive model affirms that the rate-determining step is the diffusion of D-GA through the polymeric matrix of the resin. The results obtained in this study would be useful for subsequent scaleup and optimization of operating conditions.

\section{ACKNOWLEDGEMENTS}

This work was funded by the National Natural Science Foundation of China (41606177), Industry-University Cooperation Project of Fujian Province (2015N5006), Collaborative Innovation Project of Quanzhou (2016N056), and Fujian Province Undergraduates Training Programs for Innovation and Entrepreneurship (201610399033).

\section{Reference}

1. Fukuoka, T., Ikeda, S., Habe, H., Sato, S., Sakai, H., Abe, M., Kitamoto, D., Sakaki, K., Synthesis and interfacial properties of monoacyl glyceric acids as a new class of green surfactants, J. Oleo. Sci. 61 (2012) 343. doi: https://doi.org./10.5650/jos.61.343

2. Habe, H., Fukuoka, T., Kitamoto, D., Sakaki, K., Biotechnological production of D-glyceric acid and its application, Appl. Microbiol. Biotechnol. 84 (2009) 445. doi: https://doi.org/10.1007/s00253-009-2124-3 
3. Habe, H., Sato, H., Fukuoka, T., Kitamoto, D., Sakaki, K., Effect of glyceric acid calcium salt on the viability of ethanol-dosed gastric cells, J. Oleo. Sci. 60 (2011) 585. doi: https://doi.org/10.5650/jos.60.585

4. Eriksson, C. J., Saarenmaa, T. P., Bykov, I. L., Heino, P. U., Acceleration of ethanol and acetaldehyde oxidation by D-glycerate in rats, Metabolism 56 (2007) 895. doi: https://doi.org/10.1016/j.metabol.2007.01.019

5. Habe, H., Fukuoka, T., Kitamoto, D., Sakaki, K., Biotransformation of glycerol to D-glyceric acid by Acetobacter tropicalis, Appl. Microbiol. Biotechnol. 81 (2009) 1033. doi: https://doi.org/10.1007/s00253-008-1737-2

6. Ataei, S. A., Vasheghani-Farahani, E., In situ separation of lactic acid from fermentation broth using ion exchange resins, J. Ind. Microbiol. Biotechnol. 35 (2008) 1229. doi: https://doi.org/10.1007/s10295-008-0418-6

7. Lopez-Garzon, C. S., Straathof, A. J., Recovery of carboxylic acids produced by fermentation, Biotechnol. Adv. 32 (2014) 873.

doi: https://doi.org/10.1016/j.biotechadv.2014.04.002

8. Chen, K., Lyu, H., Hao, S., Luo, G., Zhang, S., Chen, J., Separation of phenolic compounds with modified adsorption resin from aqueous phase products of hydrothermal liquefaction of rice straw, Bioresource Technol. 182 (2015) 160. doi: https://doi.org/10.1016/j.biortech.2015.01.124

9. Zhang, K., Yang, S. T., In situ recovery of fumaric acid by intermittent adsorption with IRA-900 ion exchange resin for enhanced fumaric acid production by Rhizopus oryzae, Biochem. Eng. J. 96 (2015) 38. doi: https://doi.org/10.1016/j.bej.2014.12.016

10. Jackson, J. E., Miller, D. J., Marincean, S., (Board of Trustees of Michigan State University) U.S. Pat. 7459584B2, 2 Dec 2008.

11. Caetano, M., Valderrama, C., Farran, A., Cortina, J. L., Phenol removal from aqueous solution by adsorption and ion exchange mechanisms onto polymeric resins, J. Colloid. Interface. Sci. 338 (2009) 402. doi: https://doi.org/10.1016/j.jcis.2009.06.062

12. Dehghan Monfared, A., Ghazanfari, M. H., Jamialahmadi, M., Helalizadeh, A., Adsorption of silica nanoparticles onto calcite: Equilibrium, kinetic, thermodynamic and DLVO analysis, Chem. Eng. J. 281 (2015) 334. doi: https://doi.org/10.1016/j.cej.2015.06.104

13. Foo, K. Y., Hameed, B. H., Insights into the modeling of adsorption isotherm systems, Chem. Eng. J. 156 (2010) 2. doi: https://doi.org/10.1016/j.cej.2009.09.013

14. McKay, G., Mesdaghinia, A., Nasseri, S., Hadi, M., Aminabad, M. S., Optimum isotherms of dyes sorption by activated carbon: Fractional theoretical capacity \& error analysis, Chem. Eng. J. 251 (2014) 236. doi: https://doi.org/10.1016/j.cej.2014.04.054

15. Xie, Y., Jing, K., Lu, Y., Kinetics, equilibrium and thermodynamic studies of L-tryptophan adsorption using a cation exchange resin, Chem. Eng. J. 171 (2011) 1227. doi: https://doi.org/10.1016/j.cej.2011.05.031 